\title{
Fallecimiento del profesor Gejza Mencer
}

Con gran tristeza, el CICR se enteró recientemente del fallecimiento, a los 83 años, del profesor Gejza Mencer, miembro del Comité Federal de la Cruz Roja Checoslovaca, experto de fama mundial en el ámbito del derecho internacional humanitario.

Profesor de derecho internacional público, investigador en la Academia de Ciencias checoslovaca, presidente de la Subcomisión de la Cruz Roja Checoslovaca sobre el Derecho Internacional Humanitario, el profesor Mencer se dedicó durante muchos años, en los planos tanto nacional como internacional, al desarrollo y a la difusión del derecho internacional humanitario y de los principios e ideales de la Cruz Roja. Vicepresidente, de 1979 a 1981, del Grupo Mixto CICRLiga de Sociedades de la Cruz Roja para la Difusión del Derecho Internacional Humanitario y de los Principios e Ideales de la Cruz Roja, fue delegado de la Cruz Roja Checoslovaca en la Conferencia Diplomática sobre la reafirmación y el desarrollo del derecho internacional humanitario aplicable en los conflictos armados (1974-1977) y miembro, de 1973 a 1986, de la delegación de esa Sociedad Nacional en numerosas reuniones internacionales del Movimiento Internacional de la Cruz Roja y de la Media Luna Roja. Además, dio conferencias en numerosas universidades extranjeras y es autor de obras y de estudios sobre los Protocolos adicionales a los Convenios de Ginebra, el derecho internacional público y la protección internacional del medio ambiente.

De gran sutileza de espíritu y de temperamento comunicativo, supo contagiar a muchos estudiantes su pasión por el derecho y la acción humanitarios. Su competencia profesional, su generosa personalidad y sus dotes de orador le valieron consideración y respeto, tanto en su país como en el extranjero.

En 1989, el profesor Mencer recibió la medalla Henry Dunant en reconocimiento a su incansable dedicación a la causa de la protección de la persona humana en tiempo de conflicto armado.

El CICR guardará un emocionado y agradecido recuerdo de este gran servidor de la causa humanitaria. 